Volume 8. No. 9, September 2020

International Journal of Emerging Trends in Engineering Research

Available Online at http://www.warse.org/IJETER/static/pdf/file/ijeter112892020.pdf

https://doi.org/10.30534/ijeter/2020/112892020

\title{
Taking into account the Correlated Errors of Measurements when Estimating Parameters of Object Trajectory at Mechanical Movement
}

\author{
Stanislav Piskunov ${ }^{1}$, Maksym Iasechko ${ }^{1}$, Nataliia Minko ${ }^{2}$, Yurii Dolomakin ${ }^{3}$, Oleksandr Palagin ${ }^{4}$, Marina Musorina ${ }^{4}$ \\ ${ }^{1}$ Department of Air Defense Armaments of the Land Forces, Ivan Kozhedub Kharkiv National Air Force University, Ukraine, \\ iasechko1984@ukr.net \\ ${ }^{2}$ Department of General Technical Disciplines and Drawing, T.H. Shevchenko National University "Chernihiv Collegium”, Ukraine, \\ M.NP@ukr.net \\ ${ }^{3}$ Department of Machines and Apparatuses for Food and Pharmaceutical Productions, National university of food technologies, Ukraine, \\ dyy76@ukr.net \\ ${ }^{4}$ The Department of the Occupational and Environmental Safety, Danube institute State University Odessa Marine Academy, Ukraine, \\ apalagin113@gmail.com
}

\begin{abstract}
The synthesis of a recurrent filter has been carried out, which makes it possible to take into account the slowly varying measurement error present at its input. The results of modeling the synthesized filter are presented. The expediency of applying the filter for the nonlinear correlation function of slowly varying errors of radar measurements is shown.
\end{abstract}

Key words: Radio electronic means, electromagnetic radiation, ultrashort pulse duration, plasma protection technologies, gaseous plasma media.

\section{INTRODUCTION}

In radar stations, for processing a mixture of a signal with noise and estimating the parameters of the trajectories of tracked objects, recurrent digital filters are used, which make it possible to obtain errors in estimating the parameters of trajectories that are significantly less than the errors in measuring coordinates. One of the components of the total measurement errors of radar stations are correlated errors due to various factors [1-3, 9]. Accounting for such errors is expedient in high-precision radar systems, when the fluctuation errors and correlated errors of the object coordinates are comparable in magnitude $[3,4,6]$.

An example of such systems is airborne radar stations, the position of which in space is determined by data from satellite radio navigation systems (for example, the Global Positioning System (GPS)) located on board the aircraft [5-7, 10, 11]. To eliminate the correlated error, filters can be used, synthesized on the basis of the maximum likelihood method and requiring the accumulation of measurement information for the entire observation session [2, 3, 5-10] or requiring an expansion of the vector of estimated parameters [5-7, 12-15], which makes such filters difficult to implement or reduces the quality their functioning. Therefore, it was required to develop a filter free from these disadvantages.

The purpose of the article is to synthesize a recurrent filter that allows one to take into account the slowly varying measurement error present at its input and significantly reduce its component at the output.

\section{MAIN MATERIAL}

Suppose the dimension $\mathbf{z}_{\mathrm{n}}$ at the moment $t_{n}$ is a superposition of the useful signal and errors:

$$
\mathbf{z}_{n}=\mathbf{H} \mathbf{x}_{n}+\mathbf{v}_{n}+\Delta \mathbf{b}_{n} f_{n},
$$

where $\mathbf{x}_{n}$ - vector of true values of coordinates determined by the parameters of target movement and time;

$\mathbf{v}_{\mathrm{n}}$ - vector of uncorrelated measurement errors;

$\Delta \mathrm{b}_{\mathrm{n}}$ - random vector with zero mean and given correlation matrix;

$\mathrm{f}_{\mathrm{n}}-$ known a priori nonrandom time function;

$\Delta b_{n} f_{n}=b_{n}-$ vector of correlated measurement errors of tracking coordinates;

H - operator of correspondence between measured and estimated parameters. Wherein: 
Stanislav Piskunov et al., International Journal of Emerging Trends in Engineering Research, 8(9), September 2020, 5603 - 5606

$$
\begin{aligned}
& M\left[\mathbf{v}_{n}\right]=0, M\left[\mathbf{v}_{n} \mathbf{v}_{n}^{T}\right]=\mathbf{R}_{n}, M\left[\mathbf{b}_{n}\right]=0, \\
& M\left[\mathbf{b}_{n} \mathbf{b}_{n}^{T}\right]=\mathbf{R}_{b n}, M\left[\mathbf{b}_{n} f_{n} \mathbf{b}_{n}^{T} f_{n}\right]=\mathbf{R}_{b n} f_{n}^{2} .
\end{aligned}
$$

Measurements (1) are fed to a recurrent filter that implements the smoothing operation in accordance with the expressions $[4,16-18,20-22]$ :

$$
\begin{gathered}
\mathbf{x}_{n / n-1}=\mathbf{F} \mathbf{x}_{n-1}, \\
\mathbf{P}_{n / n-1}=\mathbf{F} \mathbf{P}_{n-1} \mathbf{F}^{T}, \\
\mathbf{P}_{n}=\left(\mathbf{I}-\mathbf{K}_{n} \mathbf{H}\right) \mathbf{P}_{n / n-1}\left(\mathbf{I}-\mathbf{K}_{n} \mathbf{H}\right)^{T}+\mathbf{K}_{n} \mathbf{R}_{n} \mathbf{K}_{n}^{T}, \\
\mathbf{x}_{n}=\mathbf{x}_{n / n-1}+\mathbf{K}_{n}\left(\mathbf{z}_{n}-\mathbf{H} \mathbf{x}_{n / n-1}\right) .
\end{gathered}
$$

where $\mathbf{x}_{\mathrm{n} / \mathrm{n}-1}-$ extrapolated vector of estimated parameters;

F - extrapolation matrix;

$\mathbf{x}_{\mathrm{n}}$ - vector of estimated parameters;

$\mathbf{P}_{n}$ - correlation matrix of parameter estimates errors;

$\mathbf{P}_{n / n-1}$ - extrapolated matrix $\mathbf{P}_{n-1}$

$\mathbf{K}_{n}$ - matrix filter gain;

I - identity matrix.

When passing through the filter, correlated errors form additional parameters (errors) of the trajectory in accordance with the expression (5):

$$
\Delta \mathbf{x}_{b n}=\Delta \mathbf{x}_{b n / n-1}+\mathbf{K}_{n}\left(\mathbf{b}_{n}-\mathbf{H} \Delta \mathbf{x}_{b n / n-1}\right) .
$$

The correlation matrix of errors in estimates of trajectory parameters caused by correlated errors is by definition equal to:

$$
\mathbf{P}_{b n}=M\left[\Delta \mathbf{x}_{b n} \Delta \mathbf{x}_{b n}^{T}\right] .
$$

Substituting the value $\Delta \mathbf{x}_{b n}$ из (7) in (8) and after transforming, we get:

$$
\begin{gathered}
\mathbf{P}_{b n}=\left(\mathbf{I}-\mathbf{K}_{n} \mathbf{H}\right) \mathbf{P}_{b n / n-1}\left(\mathbf{I}-\mathbf{K}_{n} \mathbf{H}\right)^{T}+\left(\mathbf{I}-\mathbf{K}_{n} \mathbf{H}\right) \mathbf{L}_{n} \mathbf{K}_{n}^{T}+ \\
+\mathbf{K}_{n} \mathbf{L}_{n}^{T}\left(\mathbf{I}-\mathbf{K}_{n} \mathbf{H}\right)^{T}+\mathbf{K}_{n} \mathbf{R}_{b n} \mathbf{K}_{n}^{T}
\end{gathered}
$$

where $\mathbf{L}_{n}=M\left[\Delta \mathbf{x}_{b n / n-1} \Delta \mathbf{x}_{b n}^{T}\right] \quad-$ matrix of correlation coefficients between extrapolated parameters formed by correlated errors and correlated errors at the moment $t_{n}$;
$\mathbf{P}_{b n / n-1}=M\left[\Delta \mathbf{x}_{b n / n-1} \Delta \mathbf{x}_{b n / n-1}^{T}\right] \quad-\quad$ correlation matrix of extrapolated errors in parameter estimates due to correlated errors.

The total error of the parameter estimates is characterized by the total correlation matrix:

$$
\mathbf{P}_{\sum n}=\mathbf{P}_{n}+\mathbf{P}_{b n}
$$

Obviously, the optimal algorithm for recursive estimation of the trajectory parameters should provide the minimum total errors.

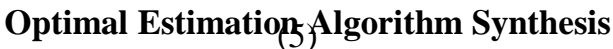

According to the posed problem of minimizing the total estimation errors, the filter gain must satisfy the condition:

$$
\mathbf{K}_{n}^{*}=\arg \min S p\left(\mathbf{H P}_{\sum n} \mathbf{H}^{T}\right) .
$$

Using an expression for matrices $\mathbf{P}_{n}$ and $\mathbf{P}_{b n}$ of (4) and (8), get:

$$
\begin{gathered}
\mathbf{H} \mathbf{P}_{\sum n} \mathbf{H}^{T}=\mathbf{H}\left(\mathbf{I}-\mathbf{K}_{n} \mathbf{H}\right) \mathbf{P}_{n / n-1}\left(\mathbf{I}-\mathbf{K}_{n} \mathbf{H}\right)^{T} \mathbf{H}^{T}+ \\
+\mathbf{H K}_{n} \mathbf{R}_{n} \mathbf{K}_{n}^{T} \mathbf{H}^{T}+\mathbf{H}\left(\mathbf{I}-\mathbf{K}_{n} \mathbf{H}\right) \mathbf{P}_{b n / n-1}\left(\mathbf{I}-\mathbf{K}_{n} \mathbf{H}\right)^{T} \mathbf{H}^{T}+ \\
+\mathbf{H}\left(\mathbf{I}-\mathbf{K}_{n} \mathbf{H}\right) \mathbf{L}_{n} \mathbf{K}_{n}^{T} \mathbf{H}^{T}+\mathbf{H K}_{n} \mathbf{L}_{n}^{T}\left(\mathbf{I}-\mathbf{K}_{n} \mathbf{H}\right)^{T} \mathbf{H}^{T}+ \\
+\mathbf{H K}_{n} \mathbf{R}_{b n} \mathbf{K}_{n}^{T} \mathbf{H}^{T}
\end{gathered}
$$

For determining $\mathbf{K}_{n}^{*}$ in accordance with (10) we find the Frechet derivative [5-12] of (11) with respect to $\mathbf{K}_{n}$ and equate it to zero:

$$
\begin{gathered}
+\mathbf{H}^{T} \mathbf{H} \mathbf{K}_{n} \mathbf{H} \mathbf{P}_{n / n-1} \mathbf{H}^{T}+\mathbf{H}^{T} \mathbf{H} \mathbf{K}_{n} \mathbf{R}_{n}- \\
-\mathbf{H}^{T} \mathbf{H} \mathbf{P}_{b n / n-1} \mathbf{H}^{T}+\mathbf{H}^{T} \mathbf{H} \mathbf{K}_{n} \mathbf{H P}_{b n / n-1} \mathbf{H}^{T}+ \\
+\mathbf{H}^{T} \mathbf{H} \mathbf{K}_{n} \mathbf{R}_{b n}+\mathbf{H}^{T} \mathbf{H} \mathbf{L}_{n}-\mathbf{H}^{T} \mathbf{H} \mathbf{K}_{n} \mathbf{H} \mathbf{L}_{n}- \\
-\mathbf{H}^{T} \mathbf{H} \mathbf{K}_{n} \mathbf{L}_{n}^{T} \mathbf{H}^{T}=\mathbf{0}
\end{gathered}
$$

Having solved (12) (wijth respect to the filter gain, we get:

$$
\begin{gathered}
\mathbf{K}_{n}^{*}=\left(\mathbf{P}_{n / n-1} \mathbf{H}^{T}+\mathbf{P}_{b n / n-1} \mathbf{H}^{T}-\mathbf{L}_{n}\right) \times \\
\times\left(\mathbf{H} \mathbf{P}_{n / n-1} \mathbf{H}^{T}+\mathbf{R}_{n}+\mathbf{H} \mathbf{P}_{b n / n-1} \mathbf{H}^{T}-\mathbf{R}_{b n}-\mathbf{H} \mathbf{L}_{n}-\mathbf{L}_{n}^{T} \mathbf{H}^{T}\right)^{-1} .
\end{gathered}
$$

Thus, the recurrent filter for estimating the parameters of the target trajectory consists of the following operations:

$$
\begin{aligned}
& \mathbf{x}_{\mathrm{n} / \mathrm{n}-1}=\mathbf{F} \mathbf{x}_{\mathrm{n}-1}, \\
& \mathbf{P}_{\mathrm{n} / \mathrm{n}-1}=\mathbf{F} \mathbf{P}_{\mathrm{n}-1} \mathbf{F}^{\mathrm{T}},
\end{aligned}
$$


Stanislav Piskunov et al., International Journal of Emerging Trends in Engineering Research, 8(9), September 2020, 5603 - 5606

$$
\begin{gathered}
\Delta \mathbf{x}_{\mathrm{bn} / \mathrm{n}-1}=\mathbf{F} \Delta \mathbf{x}_{\mathrm{bn}-1}, \\
\mathbf{P}_{\mathrm{bn} / \mathrm{n}-1}=\mathbf{F} \mathbf{P}_{\mathrm{bn}-1} \mathbf{F}^{\mathrm{T}}, \\
\mathbf{L}_{\mathrm{n}}=\mathbf{M}\left[\Delta \mathbf{x}_{\mathrm{bn} / \mathrm{n}-1} \Delta \mathbf{x}_{\mathrm{bn}}^{\mathrm{T}}\right], \\
\times\left(\mathbf{H P}_{n / n-1} \mathbf{H}_{n}^{T}+\mathbf{R}_{n}+\mathbf{H} \mathbf{P}_{b n / n-1} \mathbf{H}^{T}+\mathbf{R}_{b n}-\mathbf{H L}_{n}-\mathbf{L}_{n}^{T} \mathbf{H}^{T}\right)^{-1}, \\
\mathbf{x}_{\mathrm{n}}=\mathbf{X}_{\mathrm{n} / \mathrm{n}-1}+\mathbf{K}_{\mathrm{n}}\left(\mathbf{z}_{\mathrm{n}}-\mathbf{H} \mathbf{x}_{\mathrm{n} / \mathrm{n}-1}\right), \\
\mathbf{P}_{n}=\left(\mathbf{I}-\mathbf{K}_{n} \mathbf{H}\right) \mathbf{P}_{n / n-1}\left(\mathbf{I}-\mathbf{K}_{n} \mathbf{H}\right)^{T}+\mathbf{K}_{n} \mathbf{R}_{n} \mathbf{K}_{n}^{T}, \\
\mathbf{P}_{n}=\left(\mathbf{I}-\mathbf{K}_{n} \mathbf{H}\right) \mathbf{P}_{n / n-1}\left(\mathbf{I}-\mathbf{K}_{n} \mathbf{H}\right)^{T}+\mathbf{K}_{n} \mathbf{R}_{n} \mathbf{K}_{n}^{T}, \\
\mathbf{P}_{b n}=\left(\mathbf{I}-\mathbf{K}_{n} \mathbf{H}\right) \mathbf{P}_{b n / n-1}\left(\mathbf{I}-\mathbf{K}_{n} \mathbf{H}\right)^{T}+\left(\mathbf{I}-\mathbf{K}_{n} \mathbf{H}\right) \mathbf{L}_{n} \mathbf{K}_{n}^{T}+ \\
+\mathbf{K} \mathbf{L}_{n}^{T}\left(\mathbf{I}-\mathbf{K}_{n} \mathbf{H}\right)^{T}+\mathbf{K}_{n} \mathbf{R}_{b n} \mathbf{K}_{n}^{T}
\end{gathered}
$$

In the filter, it remains to define the method for calculating the matrix of correlation coefficients $\mathbf{L}_{n}$ and residual vectors $\mathbf{b}_{n}-\mathbf{H} \Delta \mathbf{x}_{b n}$.

With linear filtration, the following relation is valid:

$$
\Delta \mathbf{x}_{b n}=\mathbf{B}_{n-1} \mathbf{b}^{(n-1)},
$$

where $\mathbf{B}_{n-1}$ - weight matrix;

$\mathbf{b}^{(n-1)}$ - vector of $n-1$ measurements correlated errors.

Let the filtration be carried out along one coordinate $r$,

$$
\mathrm{R}_{\mathrm{bn}}=\mathrm{f}^{2}\left(\mathrm{t}_{\mathrm{n}}\right) \sigma_{\mathrm{br}}^{2}, \mathbf{b}^{(n-1)}=\Delta r_{b} \boldsymbol{\Phi}_{n-1},
$$

where $\boldsymbol{\Phi}_{n-1}=\left\|f\left(t_{1}\right), f\left(t_{2}\right), \ldots, f\left(t_{n-1}\right)\right\|^{T}$.

Then the extrapolated vector of parameters can be written as:

$$
\Delta \mathbf{x}_{b n / n-1}=\mathbf{B}_{n-1} \boldsymbol{\Phi}_{n-1} \Delta r_{b}=\mathbf{x}_{f n / n-1} \Delta r_{b},
$$

where $\mathbf{x}_{\mathrm{fn} / \mathrm{n}-1}$ - vector of errors of parameter estimates formed by sampling a nonrandom function $f(t)$.

Так как $\mathbf{b}_{n}=\Delta \mathbf{b}_{n} f_{n}=\Delta r_{b} f_{n}$, then we have

$$
\mathbf{L}_{n}=M\left[\mathbf{x}_{f n / n-1} \Delta r_{n}^{2} f_{n}\right]=\mathbf{x}_{f n / n-1} f_{n} \sigma_{r b}^{2} .
$$

Thus, separating estimates and measurements, you can write:

$$
\Delta \mathbf{x}_{b n / n-1}=\mathbf{x}_{f n / n-1} \sigma_{r b}, \mathbf{b}_{n}=\sigma_{r b} f_{n} .
$$

Then formulas (18) and (22) take the form:

$$
\mathbf{L}_{n}=\Delta \mathbf{x}_{b n / n-1} \boldsymbol{\Theta}^{T} f_{n},
$$

where $\Theta$ - вектор среднеквадратических значений амплитуды.

\section{Filter Study Results}

To assess the quality of the proposed filter, statistical modeling was carried out. As a result of modeling the dependences of the root-mean-square errors of smoothing of the parameter $r$ on the number of measurements $n$ with respect to the root-mean-square errors of uncorrelated errors, obtained from the results of 100 statistical realizations. The information update period is $T_{0}=1 \mathrm{~s}$, the root-mean-square error of uncorrelated errors in measuring the coordinate $\mathrm{r}$ is $\sigma=1 \mathrm{~m}$, root mean square error $\sigma_{\mathrm{M}}=1 \mathrm{~m}$ and $\sigma_{\mathrm{M}}=2 \mathrm{~m}$. When forming correlated errors, the function $f(t)=\sin \left(2 \pi t / T_{b}\right)$, where $T_{b}-$ correlation interval. The estimation interval of the object parameters is equal to the correlation interval $T_{b}=60 \mathrm{~s}$.

It follows from the analysis that the synthesized filter makes it possible to reduce the estimation errors of the parameter $r$ in comparison with the usual Kalman filter up to 2 times with equal uncorrelated errors and up to 3.5 times, provided that the grading exceeds the uncorrelated errors twice.

\section{CONCLUSION}

1. A synthesis of a recurrent filter has been carried out, which allows one to take into account the slowly varying measurement error present at its input.

2. The simulation results showed that, depending on the ratio of the variance of uncorrelated and correlated measurement errors, the synthesized filter can reduce the errors in estimating the parameters of the trajectory of the object in comparison with the Kalman filter by several times.

\section{REFERENCES}

1 M. Iasechko. Plasma technologies for the protection of radio electronic means from exposure to high-power electromagnetic radiations with ultrashort pulse duration, Proceedings of the 1-st Annual Conference, Tallinn, Estonia, 2017, pp. 18-21. doi: 10.21303/2585-6847.2017.00480.

2 O. Turinskyi1, M. Iasechko, V. Larin, T. Prokopenko, O. Kolmohorov, O. Salash, V. Tarshyn and Yu. Dziubenko. Determination of requirements for the protection of radio-electronicequipment from the terroristic influence by electromagnetic radiation, 
IJETER, 8(4), 2020, pp. 1333 - 1334. doi: 10.30534/ijeter/2020/64842020.

3 M. Iasechko, V. Larin, D. Maksiuta, S.Bazilo and I. Sharapa. The method of determining the probability of affection of the semiconductor elements under the influence of the multifrequency space-time signals, Journal of Critical Reviews, 7(9), 2020, pp. 569 - 571. doi: 10.31838/jcr.07.09.113.

4 O. G. Sytenko. Electromagnetic plasma fluctuations, KhGPU, Ukraine, Kharkiv, 1965, pp. 1-183.

5 S.A.Gutsev, A.A. Kudryavtsev, R.Yu. Zamchiy, V.I. Demidov, and V.I. Kolobov. Diagnostics and modeling of ashort (without positive column) glow discharge in helium with nonlocal plasma, Proc. 40th European Physical Society Conference on Plasma Physics, Finland, 2013, N 06.502.

6 M.M. Iasechko, and O.M. Sotnikov. Advanced technologies of radio electronic equipment (means) protection from powerful electromagnetic radiations with ultra short duration of pulses exposure, Published by Izdevnieciba Baltija Publishing, Collective monograph, Riga, 2018, pp.356-385.

7 M. Iasechko, N. Sachaniuk-Kavets'ka, V.Kostrytsia, V.Nikitchenko and S. Iasechko. The results of simulation of the process of occurrence of damages to the semiconductor elements under the influence of multi-frequency signals of short duration, Journal of Critical Reviews, 7(12), 2020, pp. 109 - 112. doi:10.31838/jcr.07.13.18.

8 O.Skoblikov and V. Knyazyev. Properties of Conductive Shells Exposed to Electromagnetic Impulse of Lightning, International Conference on Lightning Protection (ICLP'2012), Vienna, Austrian, 2012, pp. 1-8. pp. 402-406. doi:10.1109/TCSET49122.2020.235463.

9 M. Iasechko, M. Kolmykov, V. Larin, S.Bazilo, H. Lyashenko, P. Kravchenko, N. Polianova and I. Sharapa. Criteria for performing breakthroughs in the holes of radio electronic means under the influence of electromagnetic radiation, ARPN Journal of Engineering and Applied Sciences, 15(12), 2020, pp. 1380 - 1384.

10 O. Sotnikov, M. Iasechko, V. Larin, O. Ochkurenko, and D.Maksiuta. The model of a medium for creation of electric hermetic screens of the radio electronic means, IJATCSE. 8(2), 2019, pp. 300-304. doi:10.30534/IJATCSE/2019/32822019.

11 M. Iasechko, O. Tymochko, Y. Shapran, I. Trofymenko, D. Maksiuta, and Y. Sytnyk. Loss definition of charged particles in the discharge gap of the opening of the box-screens during the formation of a highly conductive channel, IJATCSE. 8(1.3), 2019, pp. 1-9. doi: 10.30534/ijatcse/2019/0181.32019.

12 M. Iasechko, V. Larin, O. Ochkurenko, S. Salkutsan, L. Mikhailova, and O. Kozak. Formalized Model Descriptions Of Modified Solid-State Plasma-Like Materials To Protect Radio-Electronic Means From The Effects Of Electromagnetic Radiation, IJATCSE. 8(3), 2019, pp. 393-398. doi: 10.30534/ijatcse/2019/09832019.

13 M. Iasechko, V. Larin, O. Ochkurenko, A. Trystan, T.Voichenko, A. Trofymenko, and O. Sharabaiko. Determining the function of splitting the charged particles of the strongly ionized air environment in the openings of the case-screens of radioelectronic means, IJATCSE. 8(1.3), 2019, pp. 19-23. doi: 10.30534/ijatcse/2019/0481.32019.

14 M.M. Iasechko, and O.M. Sotnikov. Protecting of radio electronic facilities is from influence of powerful electromagnetic radiation, Published by Izdevnieciba Baltija Publishing, Collective monograph, Riga, 2019, pp.283-299.

15 A. Syrotenko, O. Sotnikov M. Iasechko, V. Larin, S.Iasechko O. Ochkurenko, and A. Volkov. Model of Combined Solid Plasma Material for the Protection of Radio-Electronic Means of Optical and Radio Radiation, IJATCSE, 8(4), 2019, pp. 1241 - 1247. doi:10.30534/ijatcse/2019/33842019.

16 V. Gurevich. Electromagnetic Terrorism: New Hazards. - Electrical Engineering and Electromechanics, N 4, 2005.

$17 \mathrm{Yu}$. P. Reiser. Breakdown and heating of gases under the action of laser beam, The successes of the physical sciences, 1965.

18 A.V. Bobylev, and V.A. Chuyanov. On the numerical solution of the Landau kinetic equation, Journal of Computational Mathematics and Mathematical Physics, $T$. 16. № 2, 1977, pp. $407-416$.

19 O. Turinskyi, M. Burdin, M. Iasechko, V. Larin, Y. Gnusov, D. Ikaev, V. Borysenko, and V. Manoylo. Protection of board radioelectronic equipment from the destructive powerful electromagnetic radiation with the use of natural technologies, IJETER, 7(11), 2019, pp. 542 - 548. doi: 10.30534/ijeter/2019/237112019.

20 M. Iasechko, V. Larin, D. Maksiuta, O. Ochkurenko, I. Krasnoshapka, Y.Samsonov, H. Lyashenko, A.Zinchenko, and R.Vozniak. Model description of the modified solid state plasma material for electromagnetic radiation protection, IJETER, 7(10), 2019, pp. $376 \quad$ - 382. doi: 10.30534/ijeter/2019/027102019.

21 O. Turinskyi, M. Iasechko, V. Larin, D. Dulenko, V. Kravchenko, O. Golubenko, D.Sorokin, and O. Zolotukhin. Model and development of plasma technology for the protection ofradio-electronic means of laser emission, IJATCSE. 8(5), 2019, pp. 2429-2433. doi:10.30534/IJATCSE/2019/85852019.

22 M.Iasechko, Y. Gnusov, I. Manzhai, O. Uhrovetskyi, V.Manoylo, A. Iesipov,O. Zaitsev, M. Volk, and O. Vovk. Determination of requirements for the protection of radio-electronicequipment from the terroristic influence by electromagnetic radiation, IJETER, 7(12), 2019 , pp. $772-777$. doi: 10.30534/ijeter/2019/077122019. 